'Ilu. Revista de Ciencias de las Religiones

ISSN: $1135-4712$

http://dx.doi.org/10.5209/ILUR.57415

\title{
El 'Himno de la Perla' en el contexto de la literatura cristiano primitiva. Análisis y primeras conclusiones de HT 108-111.62
}

Israel Muñoz Gallarte ${ }^{1}$

Recibido: 5 de abril de 2017 / Aceptado: 14 de julio de 2017

Resumen. Uno quizá de los textos más bellos y enigmáticos de los Hechos apócrifos de los Apóstoles es, sin duda, el conocido como el Himno de la Perla (Hechos de Tomás 108-113), cuyo significado está lejos de encontrar un consenso en la bibliografía académica actual. Como escribió A.F.J. Klijn, en su artículo centrado en HPrl - «The So-Called Hymn of the Pearl (Acts of Thomas ch. 108-113)», Vigiliae Christianae, vol. 14, n. 3 (1960) 156-, un estudio coherente del poema debe conseguir responder a dos cuestiones principales: «What is meant with the pearl? and Who is the principal person in this hymn?». En el presente artículo se intentará dar un significado válido a este pasaje, situándolo en su debido contexto conceptual, y ofrecer una hipótesis consecuente a esas cuestiones que todavía siguen abiertas. Palabras clave: Literatura cristiana apócrifa; Hechos apócrifos de los Apóstoles; Hechos de Tomás; Himno de la Perla; Literatura griega imperial; Filosofía griega.

\section{[en] The 'Hymn of the Pearl' in the literary context of the Origins of Christianism. Analysis and first conclussions on AT 108-111.62}

\begin{abstract}
One of the most beautiful and enigmatic texts in the corpus of the Apocryphal Acts of the Apostles is beyond doubt the so-called Hymn of the Pearl (Acts of Thomas 108-113), whose meaning, however, is far from getting an academic consensus in the current bibliography. As A.F.J. Klijn in his «The So-Called Hymn of the Pearl (Acts of Thomas ch. 108-113)», Vigiliae Christianae, vol. 14, n. 3 (1960) 156, stated a coherent analysis of the poem should bring an answer to two main questions: "What is meant with the pearl? and Who is the principal person in this hymn?». The following pages will try to propose a tenable meaning to this passage by allocating it in its due conceptual context and will offer a consequent hypothesis to those questions that remain still opened.
\end{abstract}

Keywords: Apocryphal Christian Literature; Apocryphal Acts of the Apostles; Acts of Thomas; Hymn of the Pearl; Imperial Greek Literature; Greek Philosophy.

Sumario. 1. Transmisión de los Hechos de Tomás. 2. Análisis del Himno de la Perla. 2.1. Transmisión del Himno de la Perla. 2.2. Líneas generales del poema. 2.2. Comienzo del viaje (vv. 1-15). 2.3. El descenso (vv. 16-20). 2.4. Primer enfrentamiento (vv. 21-30). 2.5. Comida, sueño y olvido (vv. 31-35). 2.6. Despertar (vv. 36-56). 2.7. Segundo enfrentamiento: la perla y la serpiente (vs. 57-61). 3. Conclusiones. 4. Bibliografía.

Cómo citar: Muñoz Gallarte, I. (2017), El 'Himno de la Perla' en el contexto de la literatura cristiano primitiva. Análisis y primeras conclusiones de HT 108-111.62, en 'Ilu. Revista de Ciencias de las Religiones 22, 245-265.

\footnotetext{
1 Universidad de Córdoba (España).

E-mail: fg2mugai@uco.es
} 


\section{«I'll have them fly to India for gold, \\ Ransack the ocean for orient pearl, And search all corners of the new-found world For pleasant fruits and princely delicates». Christopher Marlowe, Dr. Faustus, vv. 84-87.}

\section{Transmisión de los Hechos de Tomás}

Pocos textos apócrifos han recibido tanta atención en los últimos años como los Hechos de Tomás $(H T)$. No sólo la literatura científica ha dedicado importantes esfuerzos para desentrañar el significado de estas páginas anónimas, sino que además las librerías especializadas en la llamada 'new age' llenan sus estanterías con los $H T$, ya sea por el atractivo que despierta el camino misionero recorrido por el apóstol, ya por las enigmáticas y bellas palabras del famoso 'Himno de la Perla' $\left(\mathrm{HPrl}^{2}\right)$.

Sin embargo, en nuestra opinión, dadas las importantes novedades que se han publicado respecto de este volumen en particular y sobre el contexto histórico-literario en que se enmarca en general -corpus de Nag Hammadi, gnosticismo, Corpus Hermeticum, heresiólogos y filosofía griega de época imperial-, merece la pena dedicar un artículo más a analizar el mencionado poema incluido en $H T$, con el interés de clarificar ciertos puntos que todavía hoy se consideran oscuros.

Con la intención de alcanzar este fin, las primeras páginas irán dirigidas a destacar brevemente las principales dificultades que presenta el Himno desde la perspectiva de la crítica textual, atendiendo especialmente a su lengua original, ya griega, ya siríaca, datación y lugar de composición. Posteriormente, se presentarán las opiniones vertidas acerca de su significado y fuentes de inspiración. Después, se propondrá un nuevo análisis de los primeros versos de HPrl -concretamente, vv. 1 a 62-a la luz del contexto en el que consideramos que debieran enmarcarse y, finalmente, se extraerán las conclusiones pertinentes.

Los $H T$, que parece haberse conservado íntegros a excepción de HPrl, han llegado hasta nosotros en dos versiones, siria y griega, transmitidas por un nutrido grupo de manuscritos. En cuanto a las ediciones realizadas a partir de los testimonios en lengua siríaca, en la que tradicionalmente se considera que fue escrito el original, consta como primera la de Wright $(1871)^{3}$, seguida por la más reciente de Burkitt y Smith Lewis $(1900)^{4}$, quienes además tomaron en consideración los nuevos hallazgos codicológicos ${ }^{5}$.

Por su parte, la versión griega ha merecido las ediciones de C. Thilo $(1823)^{6}$, las más actuales de Lipsius-Bonnet $(1903)^{7}$ y la incluida en la importante monografía de Klijn (1962) ${ }^{8}$. Para estas últimas, los autores colacionaron un número muy superior

\footnotetext{
2 HPrl ocupa los cc. 108-113. Para referirnos a algún pasaje concreto, se usará su subdivisión en versos según la edición de Lipsius - Bonnet $1972^{2}$.

Cf. Wright 1871.

4 Cf. Burkitt 1900, Appendix VII, 23-44.

5 Cabe destacar en este apartado la importante monografía de Klijn, quien traduce al inglés la versión siríaca; Klijn $2003^{2}$.

Cf. Thilo 1823 .

7 Cf. Lipsius - Bonnet $1972^{2}$.

8 Cf. Klijn $2003^{2}$.
} 
de manuscritos, pues de los cuatro de Thilo se pasa a los veintiuno de Bonnet y se añade, además, la versión griega de $\operatorname{HPrl}^{9}$. No obstante, a excepción de lo referente a la colocación de algunos capítulos en el decurso de la obra, las mejoras sólo incluyen unas pocas variantes de lectura, diferentes respecto a la edición primera de Thilo ${ }^{10}$.

A pesar de estos esfuerzos para conseguir una lectura completa de todos los pasajes incluidos en este corpus, la acribia de los editores no ha podido ocultar el accidentado carácter de la transmisión textual de estos Hechos. Tanto es así, que ni siquiera hay seguridad en lo que respecta a la lengua originaria de los $H T^{11}$. En efecto, la mayoría de los estudiosos postulan que la obra sería fruto de un viaje de ida y vuelta de la lengua siria a la helena: debió de existir un original 'fantasma' -por no conservado- en siríaco, que, poco después, habría sido vertido al griego -momento en el que sus páginas fueron profundamente modificadas bajo el tamiz del incipiente cristianismo ortodoxo ${ }^{12}$, , para, finalmente, ser traducido de nuevo de la lengua helena a una segunda versión siríaca, la que conservamos hoy día ${ }^{13}$.

¿Cuál es la base sobre la que se asienta la hipótesis de un original sirio? En primer lugar, el origen de la discusión remonta a un artículo y una nota científica a cargo de F.C. Burkitt ${ }^{14}$, a partir de la edición de W. Wright ${ }^{15}$, en los cuales se hacían eco de ciertas desviaciones, sirianismos, topónimos y antropónimos que, en su opinión, llevaban a la conclusión de que el texto griego fue una traducción de una versión siria no conservada ${ }^{16}$.

Una segunda razón de crítica textual que ha servido para apoyar la hipótesis del original sirio ha sido defendida más recientemente por Marcovich ${ }^{17}$. Ésta se refiere a la existencia en ciertos pasajes de la versión helena de los HT de lo que él llama 'Doppeldreier', esto es, un dístico con tres golpes rítmicos en cada verso. Así, en su opinión, esta versificación típicamente siríaca o aramea habría sido tenida en cuenta por el traductor griego, quien habría intentado mantenerla, según queda propuesto por Marcovich, al menos, en el conocido como 'Himno de la novia'"

Esta vía interpretativa caló en los investigadores posteriores, quienes no sólo la aceptaron, sino que la enriquecieron con nuevos argumentos, mediante una lectura que confiaba con rotundidad en la existencia de un texto sirio no conservado anterior al griego. Así Klijn, en su traducción y comentario de $H T$, escribe ${ }^{19}$ :

\footnotetext{
Cf. Myers 2010, 73-74.

10 Así, por ejemplo, tanto Lipsius - Bonnet, como Klijn, en base al texto siríaco, sitúan acertadamente el extenso rezo de Tomás tras el capítulo 144, en lugar de la colocación griega durante el martirio del apóstol, capítulo 167.

11 Cf. Klauck 2008, 141-142.

12 Klauck 2008, 142.

13 Sobre el Himno de la Perla en concreto, Myers 2010, 74, n. 52. Acerca del resto de versiones en otras lenguas de $H T$, cf. Geerard 1992, 147-152; Klauck 2008, 142.

14 Cf. Burkitt 1900, 280-290; 1901, 94-95. Más reciente es el trabajo de Attridge 1990, 241-250; Bonnet 1959, XX-XXII.

15 Cf. Roig Lanzillotta 2015, 107-108.

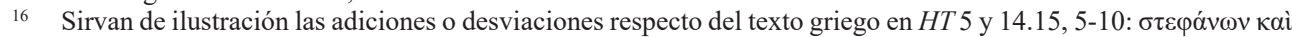

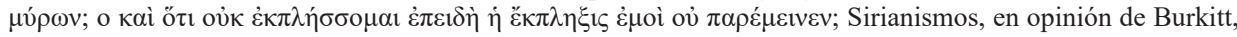

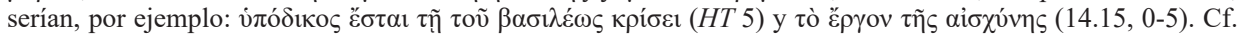
Burkitt 1900, 283-284. Contra Roig Lanzillotta 2015, 111-120; sobre antropónimos y topónimos, 120-122. Traducciones de HAA de Piñero - Del Cerro 2013.

17 Cf. Marcovich 1988, 156-157, n. 2.

18 Contra Roig Lanzillotta 2015, 108-111.

19 Cf. Klijn $2003^{2}$, 1. Así, además de los sirianismos de Burkitt, Klijn añade tres argumentos más: a) El texto sirio es más largo que el griego, como se denota especialmente en los capítulos 13, 33, 34, 59 y 70; b) La existencia de una cierta preferencia por describir el bautismo oriental en el texto sirio -esencialmente que éste se realizara
} 
The choice of this text was made because it is now generally assumed that these Acts were originally written in Syriac and secondly because the text mentioned above is the oldest integral Syriac text of this writing.

No obstante, Klijn pronto -dos páginas después- advierte que: «It is, however, too easy to assume an original Syriac text which has been translated into Greek. We suppose that the Acts were written in a bilingual environment in which both the Syriac and Greek versions originated simultaneously» ${ }^{20}$. En definitiva, se debería entender que, a pesar de lo afirmado y argumentado por la tradición, los dos textos, el sirio y el griego, fueron compuestos casi simultáneamente dentro de un contexto bilingüe.

En nuestra opinión, creemos que mantener la hipótesis de que la versión griega procede de una anterior siríaca presenta claros problemas:

En primer lugar, hay que señalar el género literario y el grupo en el que el texto suele incluirse. Dada la clara relación, a niveles conceptual y literario, entre los cinco Hechos Apócrifos más antiguos, a saber, Hechos de Juan, de Andrés, de Pedro, de Pablo y de Tomás ${ }^{21}$, parecería extraño postular para los cuatro primeros una lengua y fecha de composición del todo diversos para el quinto.

De hecho, dicha relación entre los Hechos Apócrifos fue ya percibida en la antigüedad, pues la tradición suele atribuir la composición de estos cinco a un mismo autor, Lucio Carino ${ }^{22}$. Más allá de la fiabilidad histórica que se otorgue a este dato, parece claro que esta noticia implicaría, al menos, una circulación del texto en griego ya en época temprana, pues, de lo contrario, se haría difícil comprender esta atribución, ficticia o no, de todos los textos a un mismo personaje. Por consiguiente, postular un original en la lengua siria para $H T$, mientras que el resto estuviera en griego, sería, en nuestra opinión, un sinsentido.

En tercer lugar, la cronología parece también poner un claro obstáculo a la hipótesis siríaca. Orígenes $(† 254)$ conoció $H T$, pues, según Eusebio, aquél se refirió al apócrifo en su Comentario al Génesis ${ }^{23}$. En tal coyuntura, suponer un original siríaco previo crea importantes problemas. Si, como se afirma, el texto fue escrito a principios del s. III -incluso se ha precisado su datación en torno al 230-240 24 y éste fue conocido por Orígenes en lengua griega, suponemos, habría que postular no sólo un original siríaco anterior a estos años, sino además, una rápida traducción al griego y difusión de la misma en el corto período de una o dos décadas.

en agua corriente, en un río- frente al occidental, que predominaría en el griego, aunque ya el autor advierte que en ciertos pasajes esta tendencia no se cumple; c) Ciertas omisiones del texto griego respecto del sirio o adaptaciones al cristianismo del incipiente NT (véase Klijn $2003^{2}$, 8-14). También, a este respecto, véase Drijvers 1992, 323; Piñero 2005, 868-869. Aceptan esta hipótesis recientemente García Bazán 2003, 153; Alarcón Sainz - Torijano 2006, 50; Burns 2013, 268.

20 Cf. Klijn $2003^{2}$, 3; Klauck 2008, 142. También apunta a una creación en un área siria bilingüe Myers 2010, 36, aunque mantiene la hipótesis de una rápida traducción.

21 Cf. Roig Lanzillotta 2015, 106 y n. 4, 127; Bremmer 2001, 78; ambos, a partir de Peterson 1949, 154-155.

22 Cf. Phot., Bibl. 114; cf. Drijvers 1992, 323; Schäferdiek 2003³ , 87-100.

23 Cf. Eus., $H E$ 3.1, sobre el comentario de Orígenes al Génesis.

24 Cf. Bremmer 2001, 77. También Myers 2010, 44-56, concluye que habría un primer escritor, a mediados del s. II, y un redactor que reunió todo el material en Nisibis a mediados ya del s. III (56); Alarcón Sainz - Torijano 2006, 51, apuntan al año 224 por la mención a los partos del v. 38a. 
Por tanto, coincidimos con la reciente publicación de L. Roig Lanzillotta, aceptando que ${ }^{25}$, si bien es factible que ambos textos fueran escritos en sendas lenguas durante un período y una zona bilingüe comunes -lo que explicaría el uso de términos sirios e incluso la utilización de ritmos arameos o sirios-, la posibilidad de que el texto griego sea una traducción es una hipótesis innecesaria ${ }^{26}$.

En consecuencia, esta afirmación reconfigura por completo el significado literario que hasta ahora se atribuía a los $H T$ al completo y al HPrl en particular, dado que, una vez puesta en duda la existencia de ese original siríaco 'fantasma', las fuentes de inspiración generalmente aceptadas -tendentes a encontrar en sus líneas trazas de corrientes de pensamiento orientales como Mani ${ }^{27}$, Bardesanes ${ }^{28}$ y Taciano $^{29}$-, deben ser también reevaluadas.

\section{Análisis del Himno de la Perla}

\subsection{Transmisión del Himno de la Perla}

En cuanto al poema conocido como HPrl, se conservan del mismo sendas versiones, la griega -que ha perdido el título y el colofón ${ }^{30}$ - y la siríaca ${ }^{31}$, cada una en un único manuscrito: el codex Vallicellanus B. 35 y el British Museum Add. 14645, respectivamente. A pesar de que sobre este fragmento en concreto existe una mayor unanimidad al considerar la versión griega anterior y seguramente más cercana a la original ${ }^{32}$, otro tipo de controversia le afecta, centrada en si el poema formaba parte del texto original o fue incluido en los $H T$ en una fecha posterior. Las opiniones a este respecto están absolutamente enfrentadas. En efecto, una parte de los comentaristas ${ }^{33}$ aducen que

Cf. Roig Lanzillotta 2015, 122.

Véase, a este respecto, Layton 1987, 361.

27 Véase Drijvers 1992, 337-338; Bousset 1907, 276-319; Bornkamm 1933, 115-117. No obstante, Klauck 2008, 148-149, arroja algo de luz a este respecto al confirmar que evidentemente la cronología hace imposible una influencia maniquea en $H T$, especialmente en aquellos textos que podemos considerar más antiguos, como $\mathrm{HPrl}$ - texto en el que se centran los argumentos para defender una influencia maniquea.

28 Véase Drijvers 1966 y su más reciente artículo de 1992, 322-338; también Bremmer 2001, 74, 77; van Den Bosch 2001, 136; Klauck 2008, 146. En nuestra opinión, los argumentos de orden cosmológico, teológico y ético que se aducen presentan serias contradicciones, siendo la más importante quizá la supuesta influencia encratita, a la que recientemente se ha opuesto también Myers 2010, 36-37 y n. 38.

29 Cf. Roig Lanzillotta 2015, 107; Peterson 1949, 142-162; Klijn 1960, 161 y n. 22; Klauck 2008, 177-179. Contra Drijvers 1992, 335-336. Un elemento clave que, sin embargo, separa ambas tradiciones es, en nuestra opinión, lo referido a la concepción del alma humana. Ésta última, según Taciano, fallece junto con el cuerpo y no llegará a trascender hasta el fin de los días, lo que se contrapone a la vision antropológica que ofrece $H T$ y HPrl, en especial; Tat., Orat. 13.1 y 6.1-2.

30 Cf. Drijvers 1992, 330.

31 Acerca de que HPrl fuera escrito originariamente en siríaco antiguo, cf. Mead 2006², 9-10; Klijn 1960, 154-155 y n. 4 -no obstante, el autor no se muestra igual de tajante en sus recientes publicaciones, apuntando simplemente a una comunidad del 'Cristianismo oriental', posiblemente siria, de carácter bilingüe; cf. Klijn 2001, 3 y n. 9; Marcovich 1988, 156; Drijvers 1992, 323; van Den Bosch 2001, 126. Sobre la posible publicación original de $H T$ bilingüe, cf. Layton 1987, 364.

32 Contra Nöldeke 1871, 678; Klauck 2008, 165. Cabe destacar que, si se acepta que HPrl perteneció a HT desde un inicio, como creemos, se tendría un argumento más a favor de aceptar que la lengua original del apócrifo fue la griega, dado que resultaría contradictorio que ciertas partes de la obra fueran escritas en lengua helena y otras en siríaca.

33 Se apunta a que su introducción se debió a la acción de Nicetas de Tesalónica, cf. Bonnet 1901, 161-164; Lipsius - Bonnet, 1972², XXIII; Drijvers 1992, 323-324, admite que HPrl hubo de ser añadido con posterioridad a la composición de $H T$, pero advierte que existe una relación estrecha entre ambos en cuanto a sus ideas centrales (332); Klijn 2001, 187 y n. 1; Klauck 2008, 142 y 148-149, propone que pudo ser introducido por un revisor maniqueo. 
tanto el estilo como el contenido del HPrl no tienen relación con el resto de los Hechos -lo que, por lo demás, no debe sorprender-, dada la accidentada transmisión textual de los HT. Así, consideran el texto una composición que circuló independiente y que fue añadida, tiempo después, a la composición originaria por un redactor posterior.

Otra parte de la crítica, aun asumiendo las diferencias estilísticas, reconoce importantes afinidades con el pensamiento y algunos pasajes de $H T^{34}$. Estas claras relaciones conceptuales, que se rastrean al comparar ambos textos, en nuestra opinión, no pueden explicarse a no ser que se acepte que el poema formó parte de los $H T$ desde su momento originario. En cuanto a las diferencias de tono y estilo, creemos que dos argumentos lo explican: en primer lugar, es evidente que el poeta anónimo del HPrl elige un tono mítico-legendario para plantear su mensaje en clave simbólica o alegórica que le aleja, en gran medida, de la relativa verosimilitud que busca $H T$. En segundo lugar, se observa que el poema se ha visto menos afectado por las sucesivas revisiones que sí merecieron, en cambio, los $H T^{35}$, los cuales pasaron por distintas manos que seguramente modificaron el mensaje original de los Hechos con la finalidad de argumentar sus ideologías particulares.

Con todo, en lo que se refiere a los datos de composición de la obra literaria, no puede sino concluirse que $H T$ y HPrl son un buen ejemplo de las dificultades implícitas de los textos cristiano primitivos, compuestos a finales del s. II o primera mitad del s. III de nuestra era ${ }^{36}$, en una zona oriental del Mediterráneo difícil de determinar ${ }^{37}$. En lo que respecta a su datación y autoría, como en el caso de los otros Hechos, creemos que, más allá de la legendaria adscripción a Lucio Carino, no hay todavía datos fidedignos que permitan dar una respuesta definitiva a estas cuestiones ${ }^{38}$.

\subsection{Líneas generales del poema}

El argumento de HPrl refiere un relato mitológico-legendario, cuya acción principal se centra en la figura de un joven príncipe que, aleccionado por sus padres, soberanos de una región siria, realiza un viaje cuya finalidad es encontrar una mítica perla custodiada por una serpiente. El final del trayecto será su regreso a tierra natal y la recuperación de su lugar en palacio ${ }^{39}$.

34 Cf. Luttikhuizen 2001, 114.

35 Cf. Roig Lanzillotta 2015, 106-107; en 123 escribe: «The fact that the Hymn of the Pearl has been transmitted only in two separate manuscripts belonging to two clearly separate branches of the textual transmission but also exactly in the same place and context after Thomas's imprisonment clearly speaks in favor of the primitive character of the text. That the tenor of the text in the Greek version is completely dissimilar to the rest of the Acts is due to the simple fact that it was affected to a lesser extent revision».

36 Cf. Marcovich 1988, 164; Valantasis 1999, 265, acepta la datación del texto en torno al s. III, pero advierte que partes de $H T$ proceden de una derivación filosófica y religiosa anterior, en base a lo cual debería de retrasarse la fecha de creación de ciertos pasajes. Véase, además, I. Hadot 1986, 436-459; P. Hadot $1987^{2}$.

37 De nuevo, a partir de la mención de Phot., Bibl. 114. Si Klijn propuso que HT fueron escritos en un amplio contexto como una zona de habla siria perteneciente a la Iglesia oriental -Klijn 1985, 56, 65-66; Klijn 2003² 15-, a continuación Drijvers precisó el Este de Siria -Drijvers 1992, 331; Schneemelcher 1992, 323. Posteriormente Poirier y Tissot introdujeron la hipótesis de que se tratara de Edesa -Poirier - Tissot 1997, 1324- y, finalmente, Keith Hopkins llegó a la conclusión de que el autor debería de haber sido un miembro de clase alta afincado en Edesa - Hopkins 1999, 176; también Myers 2010, 36. Klauck 2008, 146, por su parte, apunta también a Edesa. Véase también Bremmer 2001, 76.

38 A pesar de los intentos por adscribir la obra a Bardesanes o Taciano; Drijvers 1992, 324-325; Bremmer 2001, 74-79 y $154-156$.

39 Es reseñable cómo este relato, ya en sus líneas principales, encuentra claros paralelos en la literatura griega, siendo evidente relacionarlo con el viaje de Jasón y los argonautas, por ejemplo - A.R., Argonautica. Los mo- 
Así, el poema, pronunciado por Tomás al final de su periplo, mientras está encarcelado ${ }^{40}$, comienza situando la vida del protagonista en palacio, donde éste disfruta de los placeres de la vida cortesana, riqueza y lujo (vv. 1-3). El texto destaca la rica vestimenta que tejieron especialmente para él sus padres (vv. 9-10). No obstante, éstos deciden mandarlo lejos de su patria, para lo que le proveen de un hatillo en el que introducen ricas joyas provenientes de los confines de la tierra: oro, plata, rubíes, perlas y diamantes (vv. 4-8).

A continuación, el joven se despoja de sus vestiduras regias ${ }^{41}$ y abandona su lugar en palacio junto a su hermano, también heredero, aunque recibe la promesa de sus padres de que, si consigue regresar a palacio con la perla, podrá recuperar ambos (vv. 11-15). Comienza entonces un peligroso viaje que le lleva por Mesán, Babel y Sarbug, hasta Egipto, donde pierde a su escolta compuesta por dos guardianes (vv. 16-20). Se dirige el joven inmediatamente al nido de la serpiente, delante de la cual se sienta con la esperanza de que cuando ésta quede dormida pueda arrebatarle la perla (vv. 20-22).

Sin embargo, estando en soledad, se percata de que por su atuendo extranjero los egipcios podrían descubrir su verdadera naturaleza, de modo que toma los ropajes típicos egipcios para así pasar desapercibido (v. 23 y 29-30). También en este momento es cuando conoce a otro joven ${ }^{42}$ de su misma procedencia y condición, al que toma por compañero y le previene del contacto con los egipcios, denominados akathartoi (vv. 24-28). A pesar del consejo, el protagonista es víctima de los ardides de los «impuros», quienes descubren su naturaleza extranjera y por medio de una comida le hacen caer en un profundo sueño, haciéndole olvidar su naturaleza regia y la finalidad de su viaje (vv. 31-35) ${ }^{43}$.

La situación del joven es conocida en palacio y, desde allí, sus padres, su hermano y los demás nobles firman una misiva cuya finalidad es recordarle lo olvidado (vv. 36-48). Esta carta recorre ${ }^{44}$ el camino realizado por el joven, también sometida a peligros, hasta llegar al príncipe y en forma de palabra darle el comunicado (vv. 49-53). Las palabras cumplen su cometido y despiertan al joven, quien al punto se dirige contra la serpiente, pronuncia un conjuro que la deja dormida, toma la perla y, ya desnudo de los ropajes egipcios, se dirige de regreso a palacio (vv. 54-62).

tivos comunes del viaje, de los compañeros que ayudan al protagonista a realizar su empresa, de que tanto el bellocino de oro como la perla en $H T$ estén custodiados por una serpiente a la que los héroes derrotan infundiéndole un sueño y del regreso a palacio, donde reciben los honores debidos, parecen suficientes causas como para dedicar un estudio comparativo de ambos relatos que superan los límites de este artículo.

40 Lo que seguramente no es casual, si se recuerda cómo en la literatura cercana en el tiempo, por ejemplo Plutar$\mathrm{co}$, se sigue la tendencia a que la parte final de la obra sea ocupada por un mito que demuestre todo lo expuesto anteriormente -como en Pl., R. 614B-621-, Plu., De sera 563E-568; De genio 590A-593A. Igualmente, en el resto de Hechos apócrifos se observa que este lugar de la obra suele estar ocupado, como en $H T$, por el discurso más significativo del apóstol.

41 Sobre los paralelos de este despojamiento en el judaísmo, cf. Klijn 1960, 160.

42 Según Klijn 1960, 162, se trataría de Abbanes, el mercader citado en las primeras líneas de $H T$.

43 Como decíamos en n. 39, ciertos elementos acercan el poema a conocidos pasajes de la mitología griega. El sueño y el abandono del protagonista es otro motivo recurrente, como en el caso de Odiseo; Hom., Od. V, 1-176.

44 Según el texto sirio, la misiva vuela en forma de águila (vv. 51-52), pero en el griego sólo se explicita que se

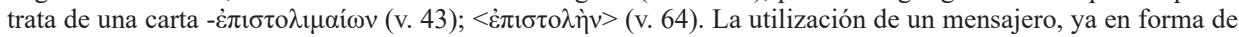
serpiente, ya en la figura misma de Cristo, que despierta y ayuda al creyente en su camino de regreso hacia la divinidad es un tópico bien atestiguado en las fuentes apócrifas; cf. ApocJn (BG 60.19-61.7); Roig Lanzillotta 2007, 547; Czachesz 2003, 87-106. 
En opinión de A.F.J. Klijn, un estudio coherente del poema debe conseguir responder a dos cuestiones principales: «What is meant with the pearl? and Who is the principal person in this hymn? ${ }^{45}$. Si bien es verdad que estas incógnitas son de gran importancia, creemos que otros muchos aspectos del mismo no lo son menos, pues su correcta interpretación puede ser de gran ayuda para una comprensión de HPrl en el contexto en que fue escrito.

En efecto, el poema ha sido extensamente interpretado por la crítica. En este aspecto, cabe destacar la visión de Theodor Nöldeke, quien en 1871 ya propuso que el joven noble expulsado de palacio debería ser considerado como el pneuma o nous, que, enviado a una lejana tierra oscura e impura como Egipto, representaría su descenso desde el ámbito divino al terrenal ${ }^{46}$. En consecuencia, el olvido del príncipe, durante su estancia terrenal simbolizaría el influjo de los placeres mundanos y la carta que le despierta de su ensueño, la revelación divina.

Sin embargo, no faltan voces en la actualidad que niegan tajantemente que el poema presentara esta inspiración. Así, Drijvers, entre otros ${ }^{47}$, defiende tajantemente:

All the characteristic marks of classic gnostic system are completely lacking. There is no mention of fall in the Pleroma; the creation is not the work of a wicked Demiurge, and matter is therefore not in itself evil. Man's freedom is the primal cause of good and evil, life and death, and this stands in sharp contrast to the gnostic determinism.

En nuestra opinión, si bien es verdad que, como algunos autores han señalado, el acercamiento de Nöldeke deja ciertos elementos sin explicar-tales como el papel de la perla, la serpiente o el significado del último ascenso del joven al palacio real ${ }^{48}$, la interpretación en clave de viaje iniciático del alma es sugestiva y enmarca el HPrl en un juego de simbología notablemente platónica y gnóstica con claras implicaciones éticas a las que pasamos a atender ${ }^{49}$.

\subsection{Comienzo del viaje (vv. 1-15)}

El principio del poema describe el lujo que acompaña al joven durante su breve estancia en las moradas paternas y una acción principal: la confección de un hatillo lleno de joyas que habrán de servir al joven en su necesario viaje para encontrar la perla $^{50}$.

45 Cf. Klijn 1960, 156.

46 Cf. Poirier 1981, 35-38. En contexto gnóstico sabemos que los peratae de Hipólito (Ref. 5.16-17) ya habían identificado Egipto con el mundo material y definido como un lugar fuera del ciclo del nacimiento donde se encuentra la «Salvación de Dios»; cf. Migne (ed.), Patrologia Graeca 15 (París, 1857) 3171C; también, Roig Lanzillotta 2010, 345-362, con abundante bibliografía al respecto.

47 Klijn 2001, 337. G. Luttikhuizen, por su parte, aunque refiere las interpretaciones en clave gnóstica de Günther Bornkamm y Werner Foester, entre otros, ofrece una condicional como conclusión: «if we wish to understand the 'Hymn of the Pearl' within its present context this conclusion makes a Gnostic interpretation of the song implausible. If it is interpreted in a Gnostic sense, it is bound to remain a corpus alienum within the ATh». Dado que el autor, posteriormente, abogará por la unidad del HPrl respecto de HT, se descarta, del mismo modo, una interpretación gnóstica -2001, 112-114.

48 Cf. Luttikhuizen 2001, 104-105.

49 Para una visión panorámica de textos y motivos recurrentes, véase García Bazán 2003, 152-153.

50 Sobre la necesidad de encarnación, HPrl se muestra igual de silencioso que gran parte de las fuentes contemporáneas. De los vv. 11-15 se entiende que se trata de una conditio sine qua non para que el joven sea «[he- 
Parte de la crítica académica ha querido ver en las piedras preciosas «el viático del Redentor para el descenso al mundo a través de las potencias del Arconte/Demiurgo, a quien(es) hay que 'pagar' un impuesto $\rangle^{51}$. Sin embargo, esta propuesta, defendida originariamente por E. Preuschen y secundada luego por Bornkamm y Foerster ${ }^{52}$, aunque sugerente por asociar el relato a un conocido motivo de raigambre gnóstica, el del salvator, salvandus -ya el Redentor ${ }^{53}$, ya el Adán del Antiguo Testamento ${ }^{54}-$, deja algunos puntos oscuros a lo largo del relato. En primer lugar, cabe señalar que la misión del protagonista se ciñe estrictamente a la recuperación de la perla, sin que la breve mención del v. 28 - «Le previne que se guardara de los egipcios / y del contacto con los impuros»-, implique que el protagonista haya salvado a alguien más, exceptuando a su propia persona. En segundo lugar, el supuesto viático no vuelve a aparecer en HPrl, ni se menciona en ningún momento pago alguno, tampoco a la figura de un Arconte/Demiurgo, que brilla por su ausencia ${ }^{55}$.

No obstante, el phorton o 'hatillo' de HPrl cobra un nuevo significado enmarcado en el contexto ético-antropológico del resto de Hechos Apócrifos y la literatura contemporánea. Desde esta perspectiva, parece más plausible interpretar las joyas que el rey da al príncipe -oro, plata, rubíes, perlas y diamantes- como las virtudes con las que el creador configura cada alma ${ }^{56}$, 'primicias' (aparché) que utópicamente deben ser conservadas durante la vida material hasta su regreso con el creador ${ }^{57}$.

Esta metáfora no es difícil de rastrear tanto en las literaturas cristiana ${ }^{58}$ y gnóstica, sobre todo de inspiración valentiniana ${ }^{59}$, como en fuentes paganas ${ }^{60}$. Así, un ejemplo dentro del mismo corpus de Hechos Apócrifos se halla en los Hechos de Juan ${ }^{61}$, en la explicación de Juan a Lycomedes acerca de cómo Jesús 'pinta' de virtudes las almas. El texto utiliza una metáfora parecida, haciendo uso del motivo de los colores en lugar de joyas, pero con mismo trasfondo: el creador usa ciertos colores que remiten a virtudes innatas en el ser humano, las cuales el individuo debe intentar conservar durante su existencia terrenal ${ }^{62}$.

redero]» en el reino de los padres. Sobre la necesidad de encarnación en la literatura cristiano primitiva y el medioplatonismo, Muñoz Gallarte 2016, 171.

51 Bonnet 1959, XX-XXII; Piñero 2005, 883, 1095, n. 564.

52 Cf. Preuschen 1933, 112; Foerster 1955, 100-114.

53 Ya sea Cristo, ya Tomás o, incluso, Mani; cf. Klijn 1960, 156 n. 8, con amplia bibliografía. No obstante, el autor apostilla que «Nowhere the word redemption, redeemer or to redeem is met» (157).

54 Se cita como apoyo a esta hipótesis los pasajes de Lucas (15,11-32) y de Mateo (13,45-46); Drijvers 1992, 31 : Adán, desposeído de sus derechos en el paraíso, desciende a la tierra para arrebatar el poder (perla) a Satán y regresar al lado del Padre. Véase además Klijn 1960, 156-157, n. 8, y 160, n. 15.

55 Únicamente se ha señalado que el demiurgo y sus potencias podrían ser interpretados por los personajes mencionados en el v. 50. No obstante, el Himno no menciona que reciban pago alguno, sino que simplemente son potenciales inconvenientes para que el protagonista reciba la carta enviada desde palacio.

56 También la de Jesús; cf. Orbe 1976, 224: «El descenso del Hijo al mundo se parece al de todos los hijos naturales de Dios, 'inmortales desde el principio', que se presentan, asimismo, en el mundo para una misión análoga a la del Unigénito».

57 Cf. Clem. Al., Ex. Thdot. 58-59. En los mismos términos, Iren. Lugd., Haer. I.6,1: «Quae enim salvaturus erat, eorum primitias eum suscepisse dicunt: ab Achamoth quidem spiritale»; cf. Orbe 1976, cit. 225-226 y nn. 48-53.

58 EvFlp 43; Hippol., Elenchos 5,17; Origenes, Hom. 13 in Ge.; Hom. 8,2 in Eu.Luc.; Meth., Symp. 1,4; 2,1; 6,2; 8,13.

59 Cf. Layton 1980, 360. Sobre el nacimiento del Salvador en TrTrip, cf. Thomassen 2006, 47-50; EvFlp 90-102, sobre Heracleón 108-112, sobre el alma del hombre, 167-168.

60 Cf. CH 5,8 y 14,8; Plut., De sera 565C-E.

61 Cf. $A J 28,6-29,19$.

62 Sobre este punto concreto y su relación con la literatura griega imperial, puede consultarse Muñoz Gallarte 2012, 235-247. 
Igualmente, en el corpus de Nag Hammadi el motivo es común ${ }^{63}$, manteniendo elementos similares: la divinidad mediante estos regalos construye el alma del individuo, habilitándolo asimismo para, tras cumplir parecidos condicionantes éticos, regresar al lugar donde fue creado. Así, en el Apócrifo de Juan las potestades van componiendo distintas partes del alma, aunando, en esta ocasión, cualidades positivas y negativas ${ }^{64}$ :

La primera, la bondad, creo un alma ósea. La segunda, la providencia, creó un alma de nervio. La tercera, la divinidad, creó un alma carnosa. La cuarta, la dominación, creó un alma de médula. La quinta, el reino, creó un alma sanguínea. La sexta, la envidia, creó un alma de piel. La séptima, comprensión, creó un alma de pelo.

Tras esto, el texto consigna cómo una multitud de ángeles, a su vez, configuran las distintas partes del cuerpo ${ }^{65}$, parecido motivo al del Sueño de Escipión I, 12.1314 , donde, haciendo uso de la metáfora astrológica, cada planeta aporta al alma en su generación y descenso las facultades o funciones anímicas ${ }^{66}$.

El motivo, de indudable raigambre platónica, podría remontar a la conocida frase de Aristóteles en su Sobre la generación de los animales 736b,38, cuando el Filósofo se refiere a la naturaleza original del alma humana en los siguientes términos: «similar al elemento del que están compuestas las estrellas» ${ }^{67}$, información que, finalmente, apuntaría al pasaje del Timeo platónico 41E, de gran predicamento en la época a la que atendemos ${ }^{68}$.

\subsection{EI descenso (vv. 16-20)}

Tras la promesa hecha por sus padres y la entrega de las joyas, el protagonista comienza el descenso a Egipto desde Oriente. El camino es definido como peligroso y difícil (dyscheré kai foberán), por lo que le acompañan unos escoltas a través de las ciudades de Mesán y Babel ${ }^{69}$. Este espacio liminal que, de nuevo, habrá de ser recorrido por el protagonista en su regreso a palacio, generalmente poblado de peligros y entidades positivas y negativas, de nuevo apunta a fuentes de raigambre platónica y gnósticas, como las antedichas ${ }^{70}$. El himno elige de las distintas posibilidades metafóricas para describir este camino la geográfica ${ }^{71}$-siendo comunes la astrológica y marina-, cumpliendo las mismas funciones: son espacios, generalmente compuestos

63 Cf. Jonas 2000, 185.

64 Cf. ApocJn 15, 14-20. Traducciones de NHC de Piñero - Montserrat Torrents - García Bazán 1997. Rudolph 1984, 102.

65 ApocJn 19, 1-10: «Todos [scil. los ángeles] colaboraron para completarlo, miembro por miembro, tanto el cuerpo psíquico como el material. Hay otros, sin embargo, sobre el resto de las pasiones, acerca de los cuales no te he hablado»».

${ }_{66}$ Sobre el origen y repercusión de este motivo a lo largo de distintas literaturas antiguas, véase Pérez 1993, 101123, especialmente 103-106. Sobre el ascenso, según Poim. 25, véase 117.

67 También Arist., Iuu. 474a 25; MA 703a 6. Cf. Brenk 1998, 41 y n. 39.

68 Cf. Elkaisy-Friemuth - Dillon 2009, 3; Dillon 1996², 376-377; Dillon 2009, 354-355; Turner 2001, 451; en 470 Turner propone que una interpretación positiva, como la que ofrece HPrl, podría haber surgido de la obra de Numenio.

69 El texto sirio completa el verso 19 con la información: et intravi moenia Sarbûg.

70 Véase Muñoz Gallarte 2016.

71 Como huída a «la patria querida», Plot., 1.6,8, 15-20; 20-25: «la patria nuestra es aquella de la que partimos, y nuestro Padre está allá». Traducciones de Plotino de Igal 1982. 
divididos en tres o cuatro etapas ${ }^{72}$, que el alma en su encarnación obligatoria debe recorrer hasta llegar al mundo material, Egipto.

La visión de Egipto y de los egipcios como elementos negativos relacionados con el mundo material o, incluso, literalmente con el 'cuerpo' humano están bien documentados en los textos gnósticos, de donde pudiera haberse inspirado el autor anónimo de HPrl. Así, por ejemplo, los peratas de Hipólito atestiguan esta interesante asimilación en los siguientes términos ${ }^{73}$ :

De acuerdo con la exegesis de los peratas, los egipcios significan los carentes de conocimiento; la salida de Egipto representa el abandono del cuerpo -Egipto denota de algún modo el cuerpo; atravesar el Mar Rojo significa atravesar el agua de la corrupción- que es Crono; alcanzar la otra orilla del Mar Rojo significa rebasar el devenir.

Esta asociación de Egipto al cuerpo y al mundo terrenal no aparece sólo en los grupos gnósticos, sino que se puede rastrear fácilmente en un amplio corpus de textos, como testimonian las menciones de Filón, Clemente de Alejandría y Orígenes ${ }^{74}$.

\subsection{Primer enfrentamiento (vv. 21-30)}

Tras el viaje, el joven llega a Egipto y se dirige directamente contra la serpiente, literalmente se sentó «cerca de su hura, / hasta que la venciera el sueño y se durmiera, / y pudiera» apoderarse de la perla ${ }^{75}$. Sin embargo, este primer intento resulta infructuoso, por lo que el joven decide mezclarse con los egipcios, para lo cual se viste «con vestiduras como las suyas» (29), a fin de que éstos no despierten a la serpiente contra el príncipe.

De nuevo, dos elementos del relato legendario, en nuestra opinión, reafirman la hipótesis respecto de que los referentes del HPrl son la literatura griega de corte platónico y el gnosticismo contemporáneos. Por un lado, estaría la noticia de que el joven se ve en la necesidad de adoptar las vestimentas egipcias, las cuales vuelven a aparecer en el v. 62 «y despojándome de sus sucios vestidos, los abandoné en su país» ${ }^{76}$.

La metáfora que asimila la última fase de la encarnación en un cuerpo humano con vestirse unos ropajes extranjeros o entrar en una jaula, cárcel o tumba es muy común en la literatura contemporánea, cuyas raíces se han buscado en la religión órfica, que sirviera, a su vez, de fuente para Platón ${ }^{77}$. El gnosticismo concibe que

Siguiendo la propuesta de Anz y Bousset, cf. Pérez Jiménez 1993, 107.

73 Hippol., Haer. 5.16,5 (trad. J. Montserrat Torrens, Los gnósticos II [Ed. Gredos: Madrid 1983]). También los Naasenos; Hippol., Haer. 5.7,39-40. En su análisis del platonismo en la Exégesis sobre el alma del códice VI de Nag Hammadi, Roig Lanzillotta 2010, 351-352 y n. 32,33 ha señalado la frecuente asociación, en el cristianismo primitivo, de Egipto con lo mundano y material.

74 Cf. Ph., De migratione Abrahami 14-15; Moses I 18-29. Véase, además, Pearce 2007, 120-122; Clem. Al., Strom. 2.47,1; 1.30,4; Origenes, Hom. 8,2 in Ex.

75 Cf. HPrl v. 22.

76 También, como envoltorios materiales en $O C$ 104, 120, 123. Sobre la necesidad de separación del alma respecto del cuerpo material Plot., Enn. I.6,6,5-15; 7,5-10: «mas la consecución del Bien es para los que suben hacia lo alto, para los que se han convertido y se despojan de las vestiduras que nos hemos puesto al bajar».

77 Cf. P1., Cra. 400BC; Grg. 493A; Roig Lanzillotta 2007, 233-235; Turner 2001, 448-450 y n. 4. Véase, no obstante, de Vogel 1981, 79-95, quien plantea importantes dudas sobre que estas ideas ya estuvieran formuladas en los diálogos platónicos con la interpretación que después recibieron. 
este paso, imprescindible para la salvación, como el que más aleja al alma de su creador, quedando ante el influjo de la heimarmene y las pasiones ${ }^{78}$. En este sentido, son claras las palabras del Apócrifo de Juan en el Corpus de Nag Hammadi, donde se lee: «Ésta es la tumba, la nueva plasmación del cuerpo, el andrajo con que los facinerosos lo vistieron, la cadena del olvido» ${ }^{79}$. Como resultado de esta acción el joven se siente alienado (toís emoís allótrios), otro elemento muy común en la literatura contemporánea como se puede comprobar en Plutarco ${ }^{80} \mathrm{o}$ en los Hechos apócrifos de Andrés: "precisamente eso es lo que el intelecto sufrió junto a ella, cuando fue roto y alienado (apolisthésas) de sí mismo» ${ }^{81}$.

Por otro lado, es claro que el texto plantea la división de dos grupos humanos, el conformado por el príncipe y el compañero de estirpe (syngené), con el que se encuentra, frente a los akáthartoi, los impuros egipcios (v. 28). En nuestra opinión, dado que la diferenciación parece establecerse ya desde el nacimiento, se debe entender que unos serían los que han recibido los dones de Dios y que, por tanto, participan de su naturaleza divina, frente a los que no los han recibido, los egipciospaganos. En cuanto a los primeros, es necesario apuntar que la posesión de estos beneficios no implica la consecución de la salvación en un sentido determinista, sino que simplemente la posibilita. Es la aceptación del mensaje, en primer lugar (vv. 55-57), y la recuperación de la perla, después (v. 61), los hechos necesarios para que el protagonista pueda regresar al palacio. En este sentido, es significativo que el protagonista advierta al 'hijo de príncipes' que se encuentra a su llegada a Egipto de los peligros que entraña mezclarse con los impuros (v. 28), pues supone que su naturaleza real -esto es, divina- no proporciona, como proponemos, la salvación de forma automática.

Un claro paralelo para esta noción aparece en los $H A$, donde se explicita que Andrés manifiesta haber sido enviado por el Señor no para enseñar nada nuevo, sino recordar a sus congéneres aquello que el contacto con la materia les había hecho olvidar. Es, por tanto, este recordatorio, no una alteración del ser, sino la actualización de su estado potencial ${ }^{82}$. La implicación de esta afirmación es que, al igual que en $H T$, la salvación del individuo no está predeterminada desde el nacimiento, pero podrá ser alcanzada, si éste habilita su estado potencial mediante la recepción del mensaje divino.

En lo que al segundo grupo antropológico se refiere, a saber, el representado por los egipcios, poco se puede entresacar de las breves referencias del poema. Nada se dice de manera explícita sobre su origen, ni tampoco acerca de la posibilidad de que éstos puedan cambiar su conducta y lograr la salvación. No obstante, parece claro que tanto ellos como su forma de vida implican el camino incorrecto, el 'yugo servil' (v. 44) $)^{83}$ al que el protagonista queda momentáneamente atado al probar su alimento inmediatamente después (trophé, vv. 32, 35).

Esta subdivisión de la humanidad en dos grupos está bien atestiguada por los heresiólogos como Ireneo, quien en su Contra las herejías destaca la visión de cier-

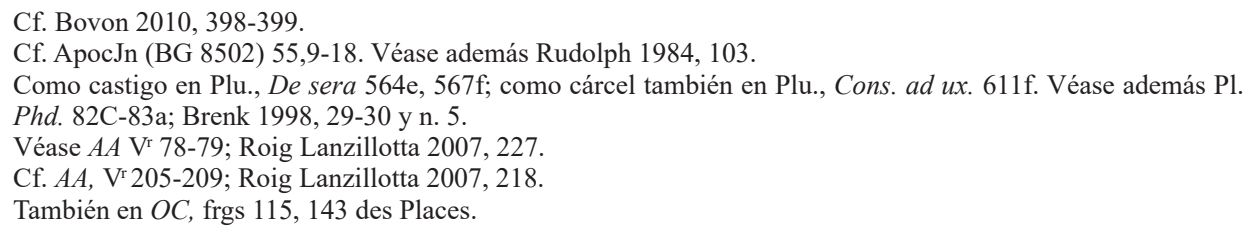


tos grupos gnósticos que separan tajantemente a los 'espirituales', es decir, aquellos para los que está reservada la salvación, frente a la 'gente material', en términos parecidos a las líneas que deducimos del $\mathrm{HPrl}^{84}$.

\subsection{Comida, sueño y olvido (vv. 31-35)}

En efecto, el joven, a pesar de sus intentos de pasar desapercibido, es descubierto (v. 31) y castigado a probar los alimentos, lo que le provoca un sueño que, en último término, conlleva el olvido de la misión encomendada.

La comida, ya desde Platón -Timeo 71D-E $\mathrm{E}^{85}$-, posee un carácter negativo basado en el principio de que 'lo similar engendra lo similar', esto es, lo perecedero y corporal produce también lo mismo, una idea de la que se hacen eco los autores posteriores:

Platón ha dicho que las cosas mortales tienen su entrada y las cosas inmortales tienen su salida. La comida y la bebida entran dentro a través del camino de la boca, comidas perecederas para un cuerpo perecedero ${ }^{86}$.

Creemos que esta concepción negativa de la comida corporal en Filón ${ }^{87}$ es la que también prevalece en los versos de $\mathrm{HPrl}$, ofreciendo una descripción del acto de comer o glotonería como la caída en las pasiones mundanas. Más explícito se muestra aún el alejandrino en 158-159, donde se expone que en el amante del placer, philédonos, que se contenta con el alimento terrenal, el placer-serpiente, según su terminología, se despierta no sólo el apetito por la comida y el vino, sino también el olvido:

(scil. el amante de los placeres-serpiente) se alimenta no del celestial manjar que ofrece la sabiduría mediante razonamientos y doctrinas (...), sino del que produce en el curso de las estaciones del año la tierra, del que proceden la embriaguez, el refinamiento en los manjares y la glotonería ${ }^{88}$.

Con todo, el contacto con lo terrenal y el dejarse llevar por los sentidos ${ }^{89}$ no sólo prolongan el estado de ignorancia del príncipe, sino que además lo incrementan, al hacerle olvidar su motivación ${ }^{90}$. De este modo, el joven queda prisionero por la realidad física. Estas tres fases: prueba del alimento ${ }^{91}$, olvido y sueño aparecen de

Iren. Lugd., Haer. 1.6,1-2; 7,5.

Cf. Runia $1986^{2}, 300$.

86 Cf. Ph., Opif. 119; alusión a Pl., Ti. 75d5-e5. Traducciones de la obra de Filón extraídas de Triviño 1976. Véase Runia $1986^{2}, 289-290$.

87 También en Ph., Opif. 23, 157-164.

88 Cf. Ph., Opif. 23, 158.

89 Obsérvese la semejanza con ExAl 129, 4-5: «pues muchas son las aflicciones que acarrea por haber abandonado su casa». Es, por tanto, el contacto con lo material lo que posibilita que el individuo se vea sometido a las pasiones; cf. Roig Lanzillotta 2010, 347-348. Véase, además, Robinson 1970, 102-117; Macrae 1972, 471-479; Ménard 1975, 56-81; Bethge 1976, 93-104.

90 El olvido de la naturaleza divina suele indicarse como un sueño también en $A A$, Vrr207, 250, 267. También como una intoxicación; cf. Roig Lanzillotta 2007, 231.

91 Véase también EnAut 31.8-15. En otros apócrifos y en NHC también es recurrente que el alma se vea seducida por un regalo, dóron; así en $A A$, V V 231-33, 252, 256; ExAl 127,29-31; PensTr 144,12-13; EvFlp 62,20-25; véase Piñero - Montserrat Torrens - García Bazán 2004, 34 n. 74. Curiosamente, Scopello 1985, 122, apunta como paralelo Longus, 15,1 . 
igual modo en el Evangelio de la Verdad ${ }^{92}$, resultando un tópico recurrente de nuevo en Filón, quien describe el olvido del alma como una borrachera, fruto del contacto del alma con lo corporal o, simplemente, como un sueño ${ }^{93}$. Igualmente, autores de la órbita medioplatónica ${ }^{94}$ o neoplatónica, como Alcínoo, Plutarco, Máximo de Tiro, Plotino y Porfirio 95 .

Significativo resulta, sin duda, la explicación que se introduce en Exposición sobre el alma (NHC 130,20-23):

La expresión 'los hijos de Egipto, hombres de carne fornida' significa el elemento carnal y sensible y las cosas de la tierra con las que el alma se contaminó en este lugar al recibir de aquéllos pan, al recibir vino, al recibir aceite, al recibir ropa y los demás perifollos que envuelven el cuerpo, cosas que ella considera innecesarias.

Aquí, al igual que en el poema, los egipcios son los causantes y símbolo de la perdición del alma individual, cuyas señales, como veíamos en escritos de corte gnóstico ${ }^{96}$, abundan en los mismos elementos: la comida, la bebida y la ropa.

\subsection{Despertar (vv. 36-56)}

A partir de este punto, el motivo del despertar del alma dormida sigue los pasos y características comunes a otros Hechos Apócrifos de los Apóstoles, describiendo, mediante la metáfora del enfrentamiento con la serpiente, el comienzo del proceso de equilibrio en el alma humana. Se inicia con la recepción del individuo de las palabras dirigidas por algún agente en directa relación con la divinidad o la divinidad misma. Tanto en 11-13 de $\mathrm{V}$ en $H A$, como en el capítulo 30 de $H J$, Andrés a Estratocles y Juan a Licomedes dirigen sus palabras a los creyentes a fin de conseguir una respuesta emocional en su alma, para que ésta, una vez despierta, intente buscar el abandono o equilibrio anímico respecto de las pasiones. Las palabras en HPrl toman la forma de una carta que llega de parte de los reyes, príncipes y nobles de Oriente (vv. 41-48) ${ }^{97}$, quienes le recuerdan un conocimiento ya adquirido durante la concepción del alma, que ahora se ve actualizado ${ }^{98} \mathrm{y}$, consecuentemente, espolea al protagonista para, una vez recordada su auténtica naturaleza, pueda enfrentarse, de nuevo y finalmente, a la serpiente (vv. 58-60).

Las raíces de esta concepción, de nuevo, apuntan a la teoría platónica de la anagnórisis, según la cual el individuo que había olvidado su propia condición necesitaba

\footnotetext{
EvV 28.32-29.11.

Véase Ph., Sobr. 2; Ebr. 15; Plant. 177; como sueño en Ad Gaium 269; Abr. 70; Somn. 1.165.

Véase Dillon 1980, 357-64.

95 Roig Lanzillotta 2007, 231-232, 236-237, propone, a este respecto, que los autores podrían haberse inspirado en la consideración del Filósofo sobre el sueño como «inactivity of the soul», EE 1219b. Véase también de Vogel $1981,89$.

96 Cf. MacRae 1972, 496-507.

97 Es reseñable que la mención del «águila mensajera» en el himno (vv. 51-52) es un añadido a partir de la copia siria, sin que en el resto del texto griego se haga mención a que la misiva adopte la forma de águila. De hecho, en

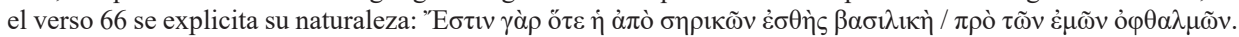
La imagen, no obstante, resulta sugestiva, en primer lugar, por la cantidad de paralelos que existen de este tópos y, en segundo lugar, por insertar los versos específicamente en este momento del poema. Véase Amsler 1999, 172; Czachesz 2003, 87-106

98 Sobre el motivo de la carta en la literatura cristiana y judía, cf. Klijn 1960, 162-163 y n. 24.
} 
reconocer su origen ${ }^{99}$. No obstante, a pesar de las similitudes, resulta imprescindible apuntar que HPrl transmite el proceso según la interpretación gnóstica, de modo que esta solución no puede ser alcanzada directamente por el individuo, sino a través de la aceptación de un mensaje divino ${ }^{100}$.

\subsection{Segundo enfrentamiento: la perla y la serpiente (vs. 57-61)}

El conflicto en clave ética al que atendemos se resuelve en los vv. 57-61 con brevedad:

Me acordé de la perla / por la que había sido enviado a Egipto, y comencé a pronunciar un conjuro / contra la terrible serpiente. / Conseguí que dormitara / pronunciando sobre ella el nombre de mi padre / Me apoderé de la perla / y me volví para dirigirme a la casa de mi padre.

Si se acepta la hipótesis de interpretación, por consiguiente, la serpiente que ahora sí es dominada por el príncipe simbolizaría las pasiones mundanas sobre las que el joven debe sobreponerse a fin de alcanzar la salvación. Esta visión, de nuevo, es un motivo frecuente en la literatura cristiano primitiva con claras influencias platónicas, como puede leerse en Filón ${ }^{101}$ :

La serpiente en cuestión es un símbolo del placer. Lo es porque, en primer lugar, se trata de un animal carente de pies, echado boca abajo y caído sobre su vientre; en segundo lugar, porque consume terrones de tierra como alimento; en tercer lugar, porque lleva en sus dientes el veneno de que la naturaleza le ha provisto para matar a los mordidos por ella.

El texto citado reproduce una interpretación de Filón respecto de la serpiente del paraíso en el contexto de Génesis, en línea también con Clemente de Alejandría ${ }^{102}$. Así, la serpiente es un símbolo de la falta de autocontrol del ser humano en base a tres semejanzas principales ${ }^{103}$, una de las cuales nos permite retomar lo afirmado acerca de la comida en HPrl: según el alejandrino tanto la serpiente, como «el amante del placer» se complacen con la comida terrenal, rechazando la celestial, esto es, la sabiduría. Si, por tanto, entendemos que la comida resulta en el juego simbólico de HPrl una abstracción de lo mundano, el escritor anónimo de HPrl se sirve del motivo del enfrentamiento contra la serpiente para personificar el esfuerzo anímico por alcanzar el autocontro ${ }^{104}$. Frente a la serpiente, Filón describe al «ofió-

99 «La tome y la besé, y commencé a leerla. Las palabras escritas eran tal como se hallaban grabadas en mi corazón» (vv. 54-5). Véase Pl., Phdr. 248c-250a; Phd. 75d, 79c; Ti. 87a-88b; Tht. 201d-202c; R. 533, 621a-621c. Sobre cómo el intelecto puede dirigir el alma a las regiones superiores una vez ha abandonado el cuerpo, véase OC 97, 109, 171.

100 Plotino, no obstante, comentando P1., Ep. VII 341C, afirma en un tono ambiguo: «Por eso dice Platón que es 'inefable' e indescriptible. Pero hablamos y escribimos acerca de él como señalando el camino a quien desee un punto de contemplación, tratando de remitirle a aquél y de despertarle de los razonamientos a la contemplación». Véase Turner 2001, 484.

101 Cf. Ph., Opif. 23, 157-158.

102 Cf. Dídimo de Alejandría, a partir seguramente de la lectura de Filón, plantea el símil de la serpiente como símbolo del placer: «placer, que es la serpiente»; cf. Gen. 95.19-21. Igualmente, Clem. Al., Prot. 111.1; Ambr., Ep. $45=34,10$. Cf. Runia 2001, 383-384

103 Cf. Ph., Opif. 23, 158-159; Runia 2001, 289-290.

104 Véase también Ph., Opif. 23, 157-158. 
maca» o luchador de la serpiente, cuyas cualidades son absolutamente contrarias, como se lee en 23,164 :

El ofiómaca, en efecto, no es, en mi opinión, otra cosa que la representación simbólica de la moderación, la que libra una batalla implacable, una guerra sin tregua contra la intemperancia y el placer.

En cuanto al significado de la perla que da título al poema ${ }^{105}$, su presencia como objeto precioso se extiende a lo largo de la literatura cristiana en general, como hemos visto, y especialmente en aquella de inspiración gnóstica. Así, por ejemplo, en EvFlp ${ }^{106} 62$ es posible leer el siguiente texto representativo:

Si la perla es arrojada al fango no se vuelve menos valiosa, ni se volverá más valiosa si es ungida con bálsamo, sino que posee siempre igual valor a los ojos de su dueño ${ }^{107}$.

Ambos textos, HPrl y EvPh, mencionan la perla como un elemento que, a pesar de encontrarse en un lugar que le es ajeno, conserva entero su valor, principalmente su vínculo con la divinidad.

El motivo es también frecuente en EvT, logia 76 y $93^{108}$ :

El Reino del Padre es semejante a un mercader, que poseía mercancía (phortion), y encontró una perla (margarites). El tal mercader era avispado. Vendió la mercancía y se compró la perla excepcional.

No deis lo santo a los perros, para que no lo arrojen al estercolero, ni arrojéis perlas a los cerdos.

Estos pasajes permiten reconocer que el símbolo de perla en HPrl remite, si se acepta la hipótesis de que su inspiración responde a un sustrato gnóstico, al nous o 'intelecto' como parte constitutiva del alma. Con este mismo significado, Ireneo se refiere en su Contra los Herejes a las tesis de Tolomeo del siguiente modo: «una

105 Thompson 1955-58, s.v. «Pearl»y «Pearls» destaca una veintena de ejemplos en los que el motivo de la perla es usado, generalmente como objeto de gran valor o mágico, custodiado por un animal. El motivo del robo de la perla a su guardián, un dragón, aparece sólo en la literatura china (B11.6.2.3), mientras que el tópico de la serpiente que custodia una joya, ya sea en su cabeza (B101.7) o en su boca (B103.4.2) resulta mucho más general, especialmente en la literatura hindú, pero también en Indonesia, U.S., Cherokee y Camerún.

106 Antología de corte gnóstico-valentiniano. En cuanto a la autoría, datación y lugar en que fue escrito, todo resulta desconocido. No obstante, algunos autores apuntan, de manera significativa para estas páginas, a Siria, como lugar más plausible, a tenor de sus menciones en lengua siríaca, y al 350 como fecha ante quem para su producción. Su lengua es el copto, aunque ésta versión pudo proceder de una traducción del griego y se conserva en el MS NHC II 51-86; cf. Layton 1987, 325-328. La valoración de la perla perdura, sin perder su significado, en los textos cristianos del s. IV, sirva de ejemplo Historia Monachorum, Paphnutius, 18, 93-95: «Te pareces al mercader que busca perlas preciosas». Esto le dice una voz celestial al anacoreta Pafnucio en referencia a su camino hacia la perfección.

107 Véase EvFlp 56, 20-26; Job 30,19; Jer. 38,6; también Iren. Lugd., Haer. I. 6,2.

108 El revisor anónimo de este artículo propone como texto con el que existen semejanzas los Hechos de Pedro y los Doce Apóstoles (NHC VI 1) -ss. II-III d.C.--, algo que ya fue advertido por Piñero - Montserrat Torrens - García Bazán 2004, 228 y notas al pie de la trad. Esta vía interpretativa, aunque resulta sugerente, dado que ambos textos comparten motivos evidentes como la perla, el viaje, el/los extranjeros, supera la finalidad de estas páginas. 
pieza de oro no pierde su belleza cuando se mete en lo sucio, sino que conserva la propia naturaleza, puesto que la suciedad no puede dañar el oro» ${ }^{109}$. Según Ireneo, Tolomeo opinaba que ese «elemento espiritual», imposible de corromper independientemente del lugar en que se encontrara o acompañado de qué estuviera, era exactamente lo que definía a los gnósticos.

Incluso fuera de la estricta literatura gnóstica, ya del NHC, ya heresiológica, similar concepción que implica una tripartición del alma, en términos parecidos a los del HPrl, incluso con el sentido de lucha alegórica por alcanzar el equilibrio anímico -algo de lo que no eran ajenos ya los textos platónicos ${ }^{110}$, se rastrea en el siguiente fragmento del $\mathrm{CH}$ IV, 4:

¿Por qué entonces, padre, Dios no ha dado participación en el Intelecto a todos? -Es porque ha querido, hijo mío, que el Intelecto fuera presentado a las almas como un premio que ellas tuvieran que ganar. - ¿Y dónde lo ha colocado entonces? -Ha llenado con él una gran crátera que ha enviado sobre la tierra, y ha apostado un heraldo con orden de proclamar a los corazones de los hombres estas palabras: «Sumérgete, tú que puedes, en esta crátera, tú que crees que volverás a ascender hacia Aquel que la ha enviado sobre la tierra, tú que sabes por qué has venido al ser».

\section{Conclusiones}

A pesar de haber analizado únicamente una primera parte del HPrl, creemos, al menos, haber clarificado, en primer lugar, la necesidad de abordar próximamente la edición y comentario, no solo del HPrl, sino de los $H T$ al completo, que, por un lado, no parta del apriorismo aceptado sobre la primacía de la versión siria sobre la griega $y$, por otro, que tenga en cuenta la dificultad intrínseca a la cual los Hechos apócrifos estuvieron sometidos, siendo copiados y modificados durante los primeros siglos de nuestra era al albur de la doctrina imperante ${ }^{111}$.

En segundo lugar y como consecuencia de lo primero, creemos que no es imprescindible, como se ha hecho hasta ahora, buscar en oriente las fuentes de inspiración del mundo conceptual de HPrl. Siendo así, se observa una importante influencia del platonismo, matizada por el tiempo que media entre el maestro y el momento en que se escribe $H T$, y del gnosticismo, especialmente. Así, según los paralelos presentados, creemos que HPrl presenta un interesante juego simbólico en el que el joven príncipe sería el alma individual; sus padres, la divinidad creadora; el descenso, el conocido motivo del descensus animae hasta la encarnación en un cuerpo humano; Egipto y los egipcios, la materia que empuja al joven a caer bajo el influjo de las pasiones; lucha que, en último término, se marca mediante los dos enfrentamientos

109 Cf. Iren. Lugd., Haer., 1.6.2. También en Plot., Enn. I.6,5, 45-55: «Expurgado esto (scil. La fealdad del alma, es decir, lo térreo), queda el oro, y el oro es bello si se aisla de las demás cosas y se queda a solas consigo mismo».

110 De Vogel 1981, 86-87, refiriéndose a Pl., Phd. 67E, afirma: «a struggle for spiritual survival by dominating the lower psychic forces which, if kept under control, may help the higher soul in its ascent but, if not, may drag it down» (87).

111 Para atender a esto se avanza la presentación de un proyecto de investigación en colaboración con el Prof. Lautaro Roig Lanzillotta (University of Groningen), cuya finalidad es la edición y comentario de la version griega de $H T$. 
con la serpiente; la lectura de la carta, la aceptación del mandado divino; la victoria definitiva, la consecución del equilibrio sobre las pasiones o metriopátheia; y, finalmente, la perla, el nous, como el elemento superior del alma humana ${ }^{112}$.

Sin duda, quedan matices a los que deseamos atender en próximas publicaciones, pero creemos que esta interpretación incluye ya algunas de las principales trazas sobre las que se deberán asentar las siguientes escenas del rico dibujo simbólico que muestra $\operatorname{HPrl}^{113}$.

\section{Bibliografía}

J. Alarcón Sainz - P.A. Torijano, «Las versiones siriaca y griega del "Himno de la perla". Introducción, traducción y notas», Coll.Ch.Or. 3 (2006) 49-81.

F. Amsler, Acta Philippi, II, Commentarius, Turnhout, 1999.

H.W. Attridge, «The Original Language of the Acts of Thomas», en H.W. Attridge (ed.), Of Scribes and Scrolls. Presented to J. Strugnell, Lanham-New York-Londres, 1990, 241250.

H. Bethge, «Die Exegese über die Seele ... eingeleitet und übersetzt vom Berliner Arbeitskreis für koptisch gnostische Schriften», Theologische Literaturzeitung 101 (1976) 93-104.

M. Bonnet, «Actes de Saint Thomas, Apôtre. Le Poème de l'âme. Version grecque remaniée par Nicetas de Thessalonique», Analecta Bollandiana XX (1901) 159-164.

M. Bonnet, Acta Apostolorum Apocrypha v. II, Leipzig, 1959.

G. Bornkamm, Mythos und Legende in den apokryphen Thomas-Akten: Beiträge zur Geschichte der Gnosis und zur Vorgeschichte der Manichäismus, Göttingen, 1933.

W. Bousset, «Hauptprobleme der Gnosis», Forschungen zur Religion und Literatur des Alten und Neuen Testaments, 10 (1907) 276-319.

F. Bovon, «The Soul's Comeback: Immortality and Resurrection in Early Christianity», Harvard Theological Review 103.4 (2010) 387-406.

J.N. Bremmer, «The Acts of Thomas: Place, Date and Women», en J.N. Bremmer (ed.), The Apocryphal Acts of Thomas, Leuven, 2001, 74-90.

F.E. Brenk, «The Origin and the Return of the Soul in Plutarch», en F.E. Brenk, Relighting the Souls. Studies in Plutarch, in Greek Literature, Religion, and Philosophy, and in the New Testament Background, Stuttgart, 1998, 28-49.

F.C. Burkitt, «Fragments of the Acts of Judas Thomas from the Sinaitic Palimpsest», en A. Smith Lewis (ed.), Select Narratives of Holy Women, Londres, 1900, Appendix VII, 23-44.

F.C. Burkitt, «The original language of the Acts of Judas Thomas», Journal of Theological Studies I (1900) 280-290.

112 Jonas, en su monografía, también inserta el símbolo de la perla en un amplio contexto gnóstico, en el cual "'pearl' is one of the standing metaphors for the 'soul' in the supranatural sense»-véase a este respecto también Klimkeit 1993, 15-17. En su opinión, el hecho de llamar al alma 'perla' se hace con la intención de precisar su valor divino y que ésta se encuentre protegida por una serpiente significaría las dificultades relacionadas con su extracción del mundo de las sombras. Aunque la hipótesis resulta seductora, creemos que el autor se equivoca al ponderar en exceso la influencia mandea, maniqueísta y del cercano oriente en general, lo que le lleva a aducir una serie de paralelos poco plausibles. Véase también Jonas 2000, 125-129.

113 Agradezco las correcciones de los revisores anónimos de la revista $\mathrm{Ilu}$, cuyas propuestas han mejorado el resultado final. 
F.C. Burkitt, «Another indication of the syriac origin of the Acts of Thomas», Journal of Theological Studies II (1901) 94-95.

D.M. Burns, «The Garment Poured Its Entire Self Over Me», en K. Corrigan - Th. Rasimus (eds.), Gnosticism, Platonism and the Late Ancient World, Leiden-Boston, 2013, 261-273.

I. Czachesz, «The Eagle on the Tree: A Homeric Motif in Jewish and Christian Literature», en F. García Martínez - G.P. Luttikhuizen (eds.), Jerusalem, Alexandria, Rome: Studies in Ancient Cultural Interaction in Honour of A. Hilhorst, Leiden, 2003, 87-106.

E. Des Places, Oracles Chaldaïques, París, 19963.

J. Dillon, «The Descent of the Soul in Middle Platonic and Gnostic Theory», en B. Layton (ed.), The Rediscovery of Gnosticism, Leiden, 1980, 357-64.

J. Dillon, The Middle Platonists, 80 BC to AD 220, Ithaca, NY $1996^{2}$.

J. Dillon, «How does the soul direct the body, after all? Traces of a dispute on mind-body relation in the Old Academy», en D. Frede \& B. Reis (eds), Body and Soul in Ancient Philosophy, Berlin - New York, 2009, 349-358.

H.J.W. Drijvers, Bardaisan of Edessa, Assen, 1966.

H.J.W. Drijvers, «The Acts of Thomas», en W. Schneemelcher, New Testament Apocrypha II, Cambridge-Louisville, 1992, 322-339.

M. Elkaisy-Friemuth - J.M. Dillon (eds.), The Afterlife of the Platonic Soul. Reflections of Platonic Psychology in the Monotheistic Religions, Leiden, 2009.

W. Foerster, «Das Wesen der Gnosis», en Die Welt als Geschichte, Stuttgart, 1955, 100-114.

F. García Bazán, La gnosis eternal. Antología de textos gnósticos griegos, latinos y coptos I, Madrid, 2003.

M. Geerard, Clavis Apocryphorum Novi Testamenti, Brepols, 1992.

I. Hadot, «The Spiritual Guide», en A. H. Armstrong (ed.), Classical Mediterranean Spirituality: Egyptian, Greek, Roman, Nueva York, 1986, 436-459.

P. Hadot, Exercises Spirituels et Philosophe Antique, París, $1987^{2}$.

K. Hopkins, A World Full of Gods, Londres, 1999.

H. Jonas (trad de Menchu Gutiérrez), La religión gnóstica. El mensaje del Dios Extraño y los comienzos del cristianismo, Madrid, 2000.

H.J. Klauck, The Apocryphal Acts of the Apostles. An Introduction, Waco, 2008.

A.F.J. Klijn, «The So-Called Hymn of the Pearl (Acts of Thomas ch. 108-113)», Vigiliae Christianae 14, n. 3 (1960) 154-164.

A.F.J. Klijn, «The Acts of Thomas Revisited», en J.N. Bremmer (ed.), The Apocryphal Acts of Thomas, Leuven, 2001, 1-10.

A.F.J., Klijn, The Acts of Thomas. Introduction, Text, Commentary, Leiden, $2003^{2}$.

Klimkeit, H.-J., Gnosis on the Silk Road, Nueva York, 1993.

B. Layton, The Gnostic Scriptures. A New Translation with Annotations and Introductions, New York, 1987.

R.A. Lipsius - M. Bonnet, Acta Apostolorum Apocrypha II.2, Leipzig, $1972^{2}$.

G.P. Luttikhuizen, «The Hymn of Jude Thomas, the Apostle, in the Country of the Indians (ATh 108-113)», in J.N. Bremmer (ed.), The Apocryphal Acts of Thomas, Leuven, 2001, 101-114.

G.W. Macrae, «A Nag Hammadi Treatise on the Soul», en Ex orbe Religionum. Studia Geo Widengren oblata, Leiden, 1972, 471-479.

M. Marcovich, «The Wedding Hymn of Acta Thomae», en Studies in Graeco-roman Religions and Gnosticism, v. IV, Leiden, 1988, 156-173.

G.R.S. Mead, Echoes from the Gnosis X. The Hymn of the Robe of Glory, Londres, $2006^{2}$.

J.-E. Ménard, «L'Evangile selon Philippe et l'Exégese de l'âme», en J.-E. Ménard (ed.), Les 
textes de Nag Hammadi: colloque du Centre d'histoire des religions, Strasbourg, 23-25 octobre 1974, Leiden, 1975, 56-81.

J.-P. Migne (ed.), Patrologia Graeca 15, París, 1857, 3171C.

J. Montserrat Torrens, Los gnósticos II, Madrid, 1983.

I. Muñoz Gallarte, «The Colours of the Soul in Plutarch and in the Apocryphal Acts of John», en L. Roig Lanzillotta - I. Muñoz Gallarte (eds), Plutarch in the Religious and Philosophical Discourse of Late Antiquity, Leiden, 2012, 235-247.

I. Muñoz Gallarte, «The Plutarch's Motive of Descensus Animae in Nag Hammadi and the Corpus Hermeticum», CFC, Estudios griegos e indoeuropeos, 26 (2016) 169-178.

I. Muñoz Gallarte, «Sobre los límites de la estemática maasiana: Los Hechos Apócrifos de Tomás y su lengua original», Creneida 4 (2016) 27-37.

S.E. Myers, Spirit Epicleses in the Acts of Thomas, Tubinga, 2010.

Th. Nöldeke, «Rev. Wright, Apocr. Acts», ZDMG XXV (1871) 670-679.

A. Orbe, Cristología Gnóstica vol. I, Madrid, 1976.

S.J.K. Pearce, The Land of the Body: Studies in Philo's Representation of Egypt, Tubinga, 2007.

A. Pérez Jiménez, «El viaje sidéreo de las almas: Origen y fortuna de un tema clásico en Occidente», Fortunatae 5 (1993) 101-123.

E. Peterson, «Bemerkungen zum Hamburger Papyrus-Fragment der Acta Pauli», Vigiliae Christianae 3 (1949) 142-162.

P.-H. Poirier, L'Hymne, Louvain-la-Neuve, 1981.

A. Piñero, Los Hechos Apócrifos de los Apóstoles, vv. I y II, Madrid, 2005 y 2013.

A. Piñero - J. Montserrat Torrens - Francisco García Bazán, Textos gnósticos. Biblioteca de Nag Hammadi I. Tratados filosóficos y cosmológicos, Madrid, 1997.

P.-H. Poirier - Y. Tissot, «Actes de Thomas», en F. Bovon - P. Geoltrain (eds.), Écrits apocryphes chrétiens I, París, 1997, 1321-1470.

E. Preuschen, Zwei gnostische Hymnen, Giessen, 1904.

W.C. Robinson, «The Exegesis on the Soul», NT 12 (1970) 102-17.

L. Roig Lanzillotta, Acta Andreae Apocrypha, Ginebra, 2007.

L. Roig Lanzillotta, «The envy of God in the Paradise Story according to the Greek Life of Adam and Eve», en A. Hilhorst - E. Puech - E. Tigchelaar (eds.), Flores Florentino: Dead Sea Scrolls and Other Early Jewish Studies in honour of Florentino Garcia Martinez, Leiden, 2007, 537-550.

L. Roig Lanzillotta, «Platonism and The Expository Treatise on the Soul (NHC II,6)», en L. Van der Stockt - F. Titchener - H. G. Ingenkamp - A. Pérez Jiménez (eds.), Gods, Daimones, Rituals, Myths and History of Religions in Plutarch's Works. Studies Devoted to Professor Frederick E. Brenk by the International Plutarch Society, Logan, Utah, 2010, 345-362.

L. Roig Lanzillotta, «A Syriac Original for the Acts of Thomas? The Hypothesis of Syriac Priority Revisited», en I. Ramelli \& J. Perkins (eds.), Early Christian and Jewish Narrative. The Role of Religion in Sharping Narrative Forms (Tubinga, 2015) 105-133.

K. Rudolph, Gnosis: The Nature and History of Gnosticism, Edimburgo, 1984.

D.T. Runia, Philo of Alexandria and the Timaeus of Plato, Leiden, $1986^{2}$.

D.T. Runia, Philo of Alexandria, On the Creation of the Cosmos according to Moses. Introduction, Translation and Commentary, Leiden - Boston - Köln, 2001.

K. Schäferdiek, «The Manichean Collection of Apocryphal Acts Ascribed to Leucius Charinus», en W. Schneemelcher (ed.), New Testament Apocrypha, II, Cambridge - Louisville, $2003^{3}, 87-100$. 
J.C. Thilo, Acta S. Thomae Apostoli, Leipzig, 1823.

E. Thomassen, The Spiritual Seed. The Church of the 'Valentinians', Leiden-Boston, 2006.

S. Thompson, Motif-Index of Folk Literature: a classification of narrative elements in folktales, ballads, myths, fables, mediaeval romances, exempla, fabliaux, jest-books, and local legends, 6 vols., Indiana, 1955-1958.

J.D. Turner, Sethian Gnosticism and the Platonic Tradition, Québec - Lovaina - París, 2001.

R. Valantasis, «The Nuptial Chamber Revisited: The Acts of Thomas and Cultural Intertextuality», Semeia 80 (1997 [1999]) 261-276.

L.P. van Den Bosch, «India and the Apostolate of Thomas», en J.N. Bremmer, (ed.), The Apocryphal Acts of Thomas, Leuven, 2001, 125-148.

C.J. de Vogel, «The Soma-Sema Formula: Its Function in Plato and Plotinus Compared to Christian Writers», en H.J. Blumenthal, R.A. Markus (eds), Neoplatonism and Early Christian Thought: Essays in honour of A.H. Armstrong, Londres, 1981, 79-95.

W. Wright, Apocryphal Acts of the Apostles, Londres, 1871. 